\title{
Uterine Angiosarcoma
}

National Cancer Institute

\section{Source}

National Cancer Institute. Uterine Angiosarcoma. NCI Thesaurus. Code C5385.

A malignant vascular neoplasm arising from the uterus. 